\title{
Growth and Characterization of the Semi Organic Non Linear Optical Crystal: Bis Thiourea Cadmium Acetate Single Crystal
}

\author{
J.Uma \\ Research Scholar, Department of Physics \\ Presidency College,Chennai
}

\author{
Dr.V.Rajendran \\ Associate Professor,Department of Physics \\ Presidency College,Chennai
}

\begin{abstract}
Single crystal of semi organic nonlinear optical material of bis thiourea cadmium acetate were grown by slow evaporation technique from its aqueous solution. The cell parameters are verified by single crystal X-ray Diffraction. Fourier transform infrared spectrum (FT-IR) is used to confirm the presence of various functional groups in the grown crystal. The thermal properties of the grown crystals are studied by thermo gravimetric analysis and differential thermal analysis (TGA and DTA). UV-vis-NIR spectra analysis shows good transmission in the optical region and near infra red region. The crystal was found to be thermally stable up to $190^{\circ} \mathrm{C}$.
\end{abstract}

Key words: growth from solutions, thermal analysis, X-ray diffraction, IR spectral analysis

\section{INTRODUCTION}

In the recent period, search for new Non Linear Optical (NLO) materials has escalated because of their applications like Second Harmonic Generation (SHG), frequency mixing, electro optic modulation, optical parametric oscillation, etc. [1].Nonlinear Optical (NLO) materials are attracting a great deal of attention due to their applications in optical devices, such as optical switches, optical modulators, optical communications, optical data storage and etc [2-3]. In search of new frequency conversion materials, recent interest focussed in semi-organic materials due to their large nonlinearity, high resistance, too large induced damage, low angular sensitivity and good mechanical hardness [4-6]. Thiourea is an interesting inorganic matrix modifier due to its large dipole moment [7] and has the ability to form extensive network hydrogen bonds. Thiourea which is centrosymmetric yields excellent non-centro symmetric materials when it is incorporated into the respective inorganic salt. [8]. Thiourea in combination with metal complexes forms semi-organic compound gives a low cutoff wavelength and it is applicable for high frequency conversion. Some of the potential thourea complex are Zinc Thiourea Chloride (ZTC) [9], Zinc Thiourea Sulphate(ZTS) [10], Bis Thiourea Cadmium Chloride (BTCC) [11], Copper Thiourea Chloride[CTC]. Bis Thiourea Cadmium Acetate (BTCA) is an efficient semi organic NLO compound [8] whose SHG efficiency is superior to KDP [12].Recently unidirectional growth of BTCA by SR method and comparative study with conventional method is carried out by V.Ganesh et.al [13]. In this paper, a large single crystal of BTCA of size $55 \times 45 \times 1 \mathrm{~mm}^{3}$ was grown by slow evaporation method.

\section{SYNTHESIS AND CRYSTAL GROWTH}

The crystal was synthesized by mixing cadmium acetate dihydrate and thiourea in the ratio of 1:2 in deionised water at room temperature. The BTCA salt was synthesized according to the reaction

$$
\mathrm{Cd}\left(\mathrm{CH}_{3} \mathrm{COO}\right)_{2}+2\left(\mathrm{CS}\left(\mathrm{NH}_{3}\right)_{2}\right) \rightarrow \mathrm{Cd}\left(\mathrm{CS}\left(\mathrm{NH}_{2}\right)_{2}\right)_{2}\left(\mathrm{CH}_{3} \mathrm{COO}\right)_{2}
$$

Purity of the synthesized salt was improved by successive recrystallization process. To avoid decomposition the solution was maintained at $45^{\circ} \mathrm{C}$ during the process. Good quality crystals has been harvested in a span of 15 days. Large crystal of size $55 \times 45 \times 1 \mathrm{~mm}^{3}$ was harvested under slow evaporation method within a month.

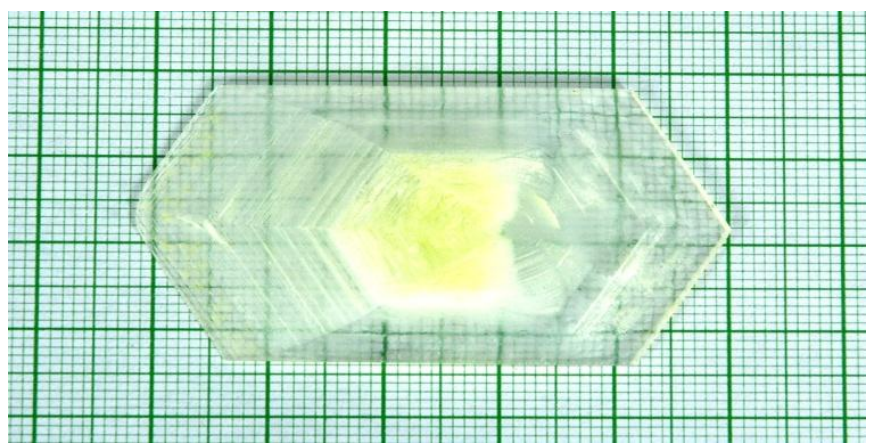

Figure 1: Bulk BTCA by slow evaporation technique

\section{CHARACTERIZATION STUDIES \\ 3.1 X-ray diffraction analysis}

The space group and cell parameters were determined by single crystal diffraction on a BRUKER axs SMART APEXII. From the X-ray diffraction data it was observed that BTCA crystal is orthorhombic in structure and with space group $\mathrm{P} 2{ }_{1}$. The lattice parameters are $\mathrm{a}=7.62 \mathrm{~A}^{\circ}, \mathrm{b}=11.83 \mathrm{~A}^{\circ}, \mathrm{c}=15.49 \mathrm{~A}^{\circ}$ and volume $=1395 \mathrm{~A}^{3}$. The crystal data is reported in Table: 1 and it agrees with the earlier reported values [14]. 
Table 1 Crystal data for BTCA crystal.

\begin{tabular}{ll}
\hline $\begin{array}{l}\text { Chemical } \\
\text { formula }\end{array}$ & $\mathrm{Cd}\left[\mathrm{CS}\left(\mathrm{NH}_{2}\right)_{2}\right]_{2}\left(\mathrm{CH}_{3} \mathrm{COO}\right)_{2}$ \\
Crystal & Orthorhombic \\
System & \\
Spacegroup & $\mathrm{P} 2_{1}$ \\
$\mathrm{a}\left(\mathrm{A}^{\mathrm{o}}\right)$ & 7.62 \\
$\mathrm{~b}\left(\mathrm{~A}^{\mathrm{o}}\right)$ & 11.83 \\
$\mathrm{c}\left(\mathrm{A}^{\mathrm{o}}\right)$ & 15.49 \\
$\alpha(\mathrm{deg})$ & 90 \\
$\beta($ deg $)$ & 90 \\
$\gamma($ deg $)$ & 90 \\
Volume $\mathrm{A}^{3}$ & 1395 \\
\hline
\end{tabular}

\subsection{FTIR Spectroscopic analysis}

The vibrational measurement was carried out at room temperature. Fourier transform infrared spectrum was obtained from potassium bromide pellets on a Perkin Elmer Spectrum1 FT-IR spectrometer. Figure 2 shows the IR spectra of BTCA crystal in the range $450-4000 \mathrm{~cm}^{-1}$. The assignments are discussed in three different regions namely high wave number region (3500-2000 $\left.\mathrm{cm}^{-1}\right)$ a medium wave number region (2000$1000 \mathrm{~cm}^{-1}$ ) and a low wave number region (below $1000 \mathrm{~cm}^{-1}$ ). In the high wave number region the vibrational spectra consist of $\mathrm{NH}_{2}$ and $\mathrm{CH}_{2}$ stretching vibrations and the combination of these functional groups. A sharp absorption band at $3429 \mathrm{~cm}^{-1}$ is the region of $\mathrm{OH}$ or $\mathrm{NH}_{2}$ band vibration. The wave numbers $3304 \mathrm{~cm}^{-1}, 3137 \mathrm{~cm}^{-1}$ and $2767 \mathrm{~cm}^{-1}$ region are assigned on $\mathrm{CH}_{2}$ stretching. The medium wave number ranges are assigned on carbon double bond stretching with oxygen and $\mathrm{CH}_{2}$ bending vibrations. The strong peak at $1415 \mathrm{~cm}^{-1}$ corresponds to $\mathrm{O}-\mathrm{H}$ stretching. The bands at $1018 \mathrm{~cm}^{-1}$ and $1050 \mathrm{~cm}^{-1}$ are assigned to $\mathrm{C}-\mathrm{OH}$ stretching. The low wave numbers $783 \mathrm{~cm}^{-1}$ and $725 \mathrm{~cm}^{-1}$ are assigned to $\mathrm{C}-\mathrm{H}$ stretching and $\mathrm{C}-\mathrm{H}$ rocking respectively. The observed wave numbers and the proposed assignments are listed in Table 2. It is in agreement with earlier reported values. [15]

Table: 2 Wave number of absorption peaks in FTIR ,spectrum and their assignments of BTCA

\begin{tabular}{cc}
\hline FTIRcm $^{-1}$ & Mode Assignments \\
\hline 3429 & $\mathrm{OH} / \mathrm{NH}_{2}$ stretching \\
3304 & $\equiv \mathrm{CH}$ stretching \\
3137 & $=\mathrm{CH}_{2}$ stretching \\
2767 & $\mathrm{C}-\mathrm{H}$ bending \\
1664 & $\mathrm{C}=\mathrm{C}$ stretching \\
1630 & $\mathrm{C}=\mathrm{O}$ stretching \\
1560 & $\mathrm{C}=\mathrm{O}$ stretching \\
1494 & $\mathrm{CH}_{2}$ bending \\
1415 & $\mathrm{O}-\mathrm{H}$ stretching \\
1110 & $\mathrm{C}=\mathrm{S}$ stretching \\
1050 & $\mathrm{C}-\mathrm{OH}$ stretching \\
1018 & $\mathrm{C}-\mathrm{OH}$ stretching \\
942 & $\mathrm{C}-\mathrm{H}_{1}$ stretching \\
783 & $\mathrm{CH}$ rocking \\
725 & $\mathrm{CH}_{2}$ rocking \\
\hline
\end{tabular}

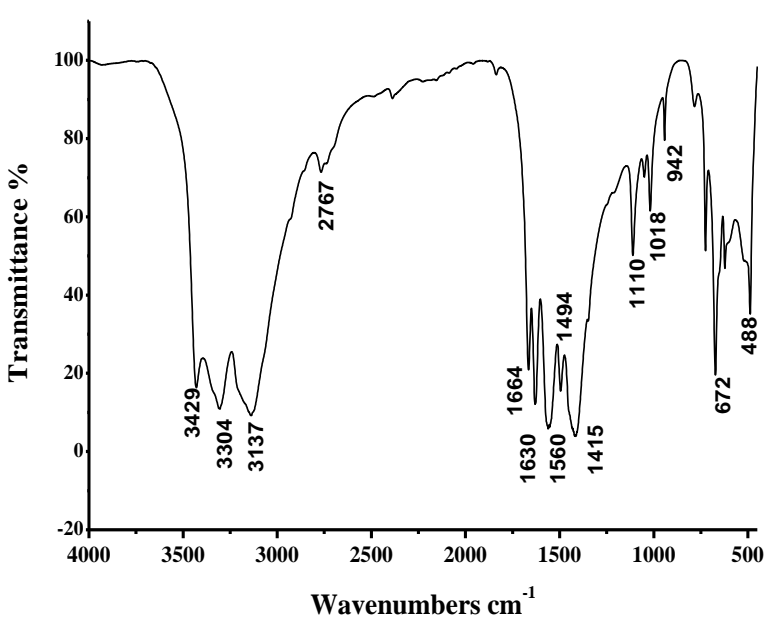

Figure 2 IR Spectra for BTCA

\subsection{UV-vis-NIR spectral analysis}

The UV-vis-NIR spectrum (Fig.3) for BTCA crystal was studied using a Cary Varrian UV-vis-NIR spectrophotometer in the range of $200-2000 \mathrm{~nm}$. It is seen that a strong absorption band occurs at $800 \mathrm{~nm}$ and this absorption is due to $n \rightarrow \pi^{*}$. The lower cut wavelength is due to the $\pi \longrightarrow \pi^{*}$ transitions. With the transmission window between $900 \mathrm{~nm}$ to $1500 \mathrm{~nm}$, it is evident that the crystal can be used for second harmonic generation in the near IR region using lasers having wavelength of $1000 \mathrm{~nm}$ and $1200 \mathrm{~nm}$.

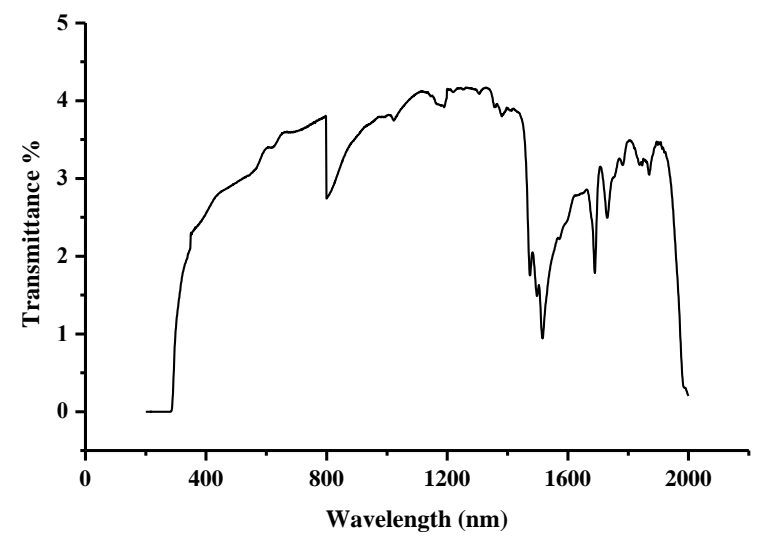

Figure 3 Transmission spectra of BTCA crystal

\subsection{Thermal studies}

Simultaneous Thermo Gravimetric Analysis (TGA) and Differential Thermal Analysis (DTA) were carried out for BTCA crystal using TGA Q500 V20.10 Build 36 thermal analyzer. The characteristic curves are shown in Figure 4. A powder sample was used for the analysis in the temperature range of $28^{\circ} \mathrm{C}$ to $830^{\circ} \mathrm{C}$ with a heating rate of $20^{\circ} \mathrm{C}$ per minute in the nitrogen atmosphere. Initial decomposition of the compound starts at $130^{\circ} \mathrm{C}$. The studies reveal that BTCA is thermally stable up to $190^{\circ} \mathrm{C}$ after this the sample undergone appreciable weight loss up to $56.18 \%$. The change in weight loss confirmed the 
decomposition nature of the sample. Differential thermal analysis confirms through a sharp endothermic peak at $191^{\circ} \mathrm{C}$ which corresponds to the melting point of the sample. There is no weight loss below $100^{\circ} \mathrm{C}$ which shows that there is no water molecule in the sample. Further degradation of the sample takes place above $330^{\circ} \mathrm{C}$ to $600^{\circ} \mathrm{C}$ where the loss of weight is about $6.646 \%$ due the liberation of ammonia molecule. The later mass loss of $5.976 \%$ is due to the release of $\mathrm{CO}$ and $\mathrm{C}_{2} \mathrm{H}_{4}$ in third stage of decomposition ranges from $600^{\circ} \mathrm{C}$ to $830^{\circ} \mathrm{C}$ and leaving a residue of CdS. A study of thermal decomposition of Cadmum Thiourea coordination compounds by V.N.Semenov et al in 1999 confirmed the residue as CdS [16].

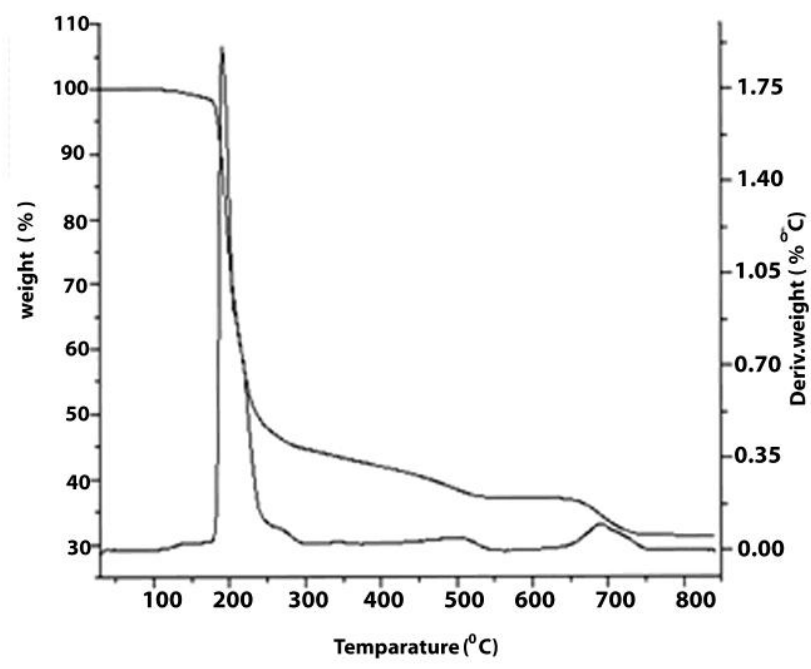

Figure 4 TG/DTA Curve for BTCA crystal

\section{CONCLUSION}

In this paper a semi organic nonlinear material of Bis Thiourea Cadmium Acetate (BTCA) was synthesized under slow evaporation method. The grown crystal is confirmed by single crystal X-ray diffraction study. FTIR spectrum is discussed to confirm the various functional groups in the grown crystal. The transmission was determined by UV-vis-NIR spectra. Thermal analysis has been carried out and the melting point of the sample and various decomposition stages was determined.

\section{REFERENCES}

[1] D.S. Chemla and J. Zyss, Academic Press, London (1987).
[2] Marcy H.G,Waarren L.F,Webb M.S,Ebbrs C.A,Velslo S.P,Kennedy G.C, and Catela G.C,Appl.Opt, 31(1992)5052.

[3] Hou W.B,Jang M.H,Yuan D.R,Xu D,Zhang N,Liu M.G and Tau mater.Res.bul(1993) 28,645.

[4] Xing G,Jiang M, Zishao X and Xu D J. Lasers 14(1987) 357

[5] Versko S,Laser Program Annual Report, Lawrence UCRCJC 105000,Lawrence Livermore National Laboratory Livermore, CA. (1990).

[6] Warren L.F, Electronic Materials our future in: Allred R.E, Martinez R.J, Wischmann K.B, (Eds), Proceedings of the Foruth International Sample Electronics Society for the Advancement of Materials and Process Engineering Of Materials and Process Engineering, Covina, (1990)CA,Vol.4 .p. 388.

[7] Landott Bornstein In: K.H.Hettwege, A.M.Hellwege (Eds) ,Numerical Date And Functional Relationship In Science And Technology,(1982)Group, 14, Springer, Berlin.p.584.

[8] V.Kannan, N.P.Rajesh, R.Bairava Ganesh, P.Ramasamy, J.Crystal Growth(2004) 269, 565-569.

[9] Ushashree P.M, Jayavel R, Subramanium C and Ramasamy P, J.Crystal Growth(1990) 197, 216-220.

[10] Rajasekaran R, Ushashree P.M, Jayavel R, Ramasamy P, J.Crystal Growth(2001) 229,563-567.

[11] Ushashree P.M,Muralidharan R, Jayavel R and Ramasamy P, J.Crystal Growth(2000) 218, 365-371.

[12] R. Sankar, C.M. Raghavan and R. Jayavel. Cryst. Res. Technol., 41 (2006), p. 919.

[13] V. Ganesh, Ch. Snehalatha Reddy, Mohd. Shakir, M.A. Wahab, G. Bhagavannarayana, K. Kishan Rao, Physica B: Condensed Matter,(2011),Vol 406,2, pp 259-264.

[14] Rajesh N.P, Kannan V,Ashok M,Shivaji K, Santhanaraghavan $\mathrm{P}$ and Ramasamy P J.Crystal Growth(2004) 262, 561-566.

[15] S. Selvakumar, S.M. Ravi Kumar, Ginson P. Joseph, K. Rajarajan, J. Madhavan, S.A. Rajasekar, P. Sagayaraj, Materials Chemistry and Physics, (2007) Vol 103, Issue 1, pp 153-157

[16] Semenov V.N, Naumov A.V, Russian Journal Of General Chemistry,(2001)Vol.71, No:4, pp. 495-499 (2001), Translated From Zurnal Obshchei Kimeii,(2001) Vol. 71, No:4, pp. 533-537 (2001). 